Article

\title{
Real-Time City-Scale Time-History Analysis and Its Application in Resilience-Oriented Earthquake Emergency Responses
}

\author{
Xinzheng Lu ${ }^{1, *(1)}$, Qingle Cheng ${ }^{2}$, Zhen $\mathrm{Xu}^{3}$, Yongjia $\mathrm{Xu}^{2}$ and Chujin Sun ${ }^{2}$ \\ 1 Key Laboratory of Civil Engineering Safety and Durability of China Education Ministry, Department of \\ Civil Engineering, Tsinghua University, Beijing 100084, China \\ 2 Beijing Engineering Research Center of Steel and Concrete Composite Structures, Tsinghua University, \\ Beijing 100084, China \\ 3 School of Civil and Environmental Engineering, University of Science and Technology Beijing, \\ Beijing 100083, China \\ * Correspondence: luxz@tsinghua.edu.cn; Tel.: +86-10-6279-5364
}

Received: 6 July 2019; Accepted: 21 August 2019; Published: 24 August 2019

\begin{abstract}
The resilience of cities has received worldwide attention. An accurate and rapid assessment of seismic damage, economic loss, and post-event repair time can provide an important reference for emergency rescue and post-earthquake recovery. Based on city-scale nonlinear time-history analysis (THA) and regional seismic loss prediction, a real-time city-scale time-history analysis method is proposed in this work. In this method, the actual ground motion records obtained from seismic stations are input into the building models of the earthquake-stricken area, and the nonlinear time-history analysis of these models is subsequently performed using a high-performance computing platform. The seismic damage to the buildings in the target region subjected to this earthquake is evaluated according to the analysis results. The economic loss and repair time of the earthquake-stricken areas are calculated using the engineering demand parameters obtained from the time-history analysis. A program named, "Real-time Earthquake Damage Assessment using City-scale Time-history analysis" ("RED-ACT" for short) was developed to automatically implement the above workflow. The method proposed in this work has been applied in many earthquake events, and provides a useful reference for scientific decision making for earthquake disaster relief, which is of great significance to enhancing the resilience of earthquake-stricken areas.
\end{abstract}

Keywords: city-scale nonlinear time-history analysis; real-time city-scale time-history analysis; resilience-oriented earthquake emergency response; multiple-degree-of-freedom (MDOF) model; ground motion records

\section{Introduction}

Earthquakes cause severe damage and economic loss to urban areas, and the resilience of cities has received worldwide attention. An accurate and rapid assessment of seismic damage, economic loss, and post-event repair time can provide an important reference for emergency rescue and post-earthquake recovery. Therefore, it is of great importance to the enhancement of community resilience.

The experience of several major earthquakes in recent years indicates that the assessment of building damage in an earthquake-stricken area needs to be improved further. After an earthquake, communication in the disaster area is delayed; the disaster site is usually chaotic, and there are not enough professionals to evaluate building safety in a short time. Furthermore, rumors and fake information on the internet may interfere with accurate seismic damage assessment. Therefore, it is necessary to propose a scientific, objective, and timely method for earthquake loss assessment. 
To date, available near-real-time loss estimation tools can be divided into two categories based on the size of the area they cover: (1) Global systems and (2) local systems [1]. Global near-real-time earthquake loss estimation tools primarily include the Prompt Assessment of Global Earthquakes for Response (PAGER) [2], the Global Disaster Alert and Coordination System (GDACS) [3], and the World Agency of Planetary Monitoring and Earthquake Risk Reduction (WAPMERR) [4]. Local systems include the Earthquake Rapid Reporting System in Taiwan; USGS-ShakeCast, Istanbul's earthquake rapid response system; and the Rapid Response and Disaster Management System in Yokohama, Japan [5]. These seismic loss estimation systems are generally comprised of three parts: The ground motion intensity measure (IM), building inventory and fragility, and direct economic losses and casualties. The ground motion IM can be obtained directly from the real-time monitoring data of a seismic network or calculated using ground motion prediction equations (GMPE). The building inventory data can be determined using either a detailed building database or macroscopic statistical data. The seismic damage to buildings can be predicted using the damage probability matrix (DPM) method [6], the capacity spectrum method [7], or artificial intelligence-based methods [8,9]. Economic losses and casualties are generally calculated using empirical models.

However, the main problems existing in these systems are as follows: (a) The dynamic characteristics of ground motion are not comprehensively considered; (b) the DPM method is difficult to apply in areas where historical earthquake data are lacking or in quickly developing areas where there are large differences between the inventories of current and historical buildings; (c) the capacity spectrum method cannot easily represent the concentration of damage to different stories or the time-domain properties of ground motions (e.g., the velocity impulse of ground motions); (d) the earthquake loss prediction method relies on historical seismic damage data, and the repair time cannot be provided in these systems.

Consequently, this work proposes a real-time city-scale time-history analysis method for post-earthquake damage assessment. The actual ground motion records obtained from seismic stations were input into the building models of the earthquake-stricken area, and the nonlinear time-history analysis of these models was subsequently performed. The seismic damage, economic loss, and repair time of the target region subjected to this earthquake were evaluated according to the analysis result. A program, named "Real-time Earthquake Damage Assessment using City-scale Time-history analysis" (or "RED-ACT" for short), was developed. The application and the advantages of the proposed method were demonstrated through actual earthquake events.

\section{Real-Time City-Scale Nonlinear Time-History Analysis}

\subsection{Framework}

The proposed framework to conduct the real-time city-scale time-history analysis and loss assessment is illustrated in Figure 1. The corresponding procedures are as follows:

(1) Obtaining the real-time ground motion records from the seismic stations;

(2) Establishing the building inventory database for the target region;

(3) Conducting the city-scale nonlinear time-history analysis to predict the seismic damage of the target region; and

(4) Performing the regional seismic loss prediction to assess the seismic economic loss and repair time of the target region. 


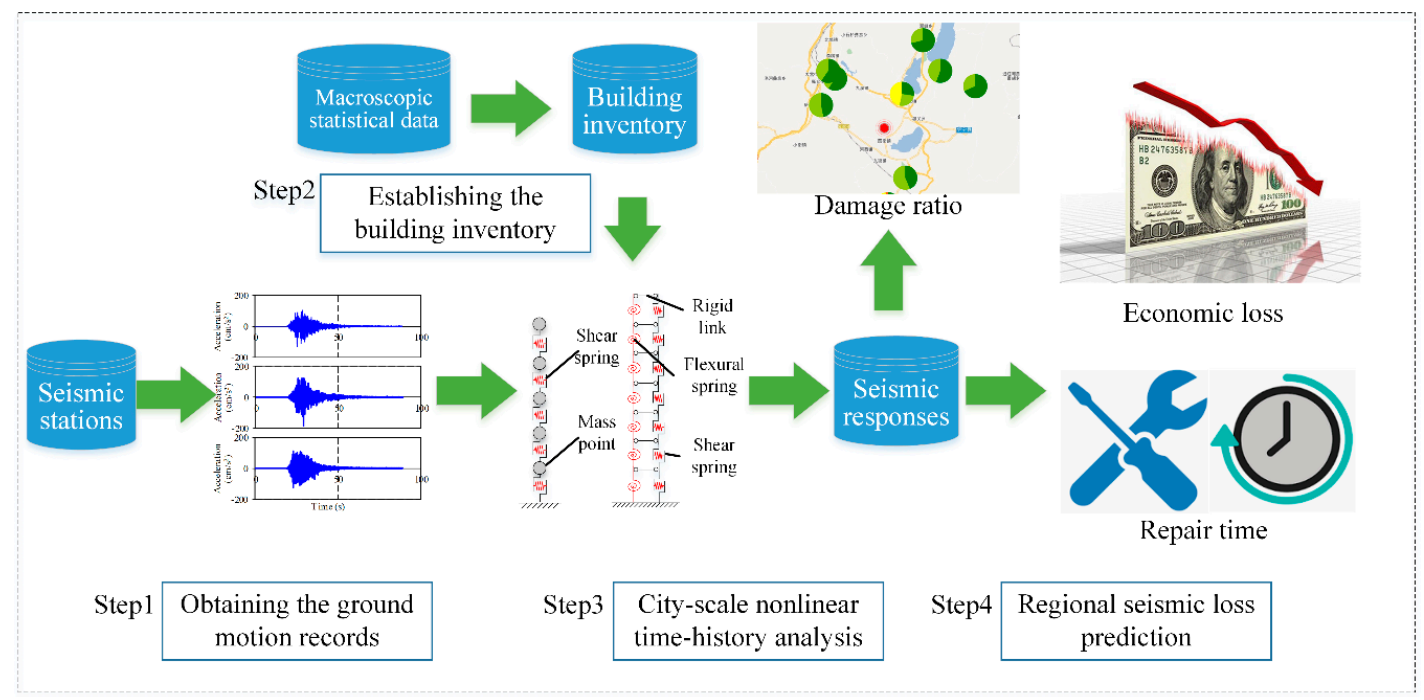

Figure 1. Framework for real-time city-scale time-history analysis and loss assessment.

\subsection{Real-Time Recorded Ground Motions}

The ground motion records can fully describe the features of the ground motions with no information loss. The densely distributed seismic stations and communication network make it possible to obtain the real-time ground motion records. After an earthquake, the ground motion record near the epicenter can be quickly obtained through the seismic stations and communication network, and information, such as the station's latitude, longitude, and recording time, can be collected simultaneously. With the development of monitoring and data-transforming technology, the densely distributed strong motion network will cover more regions, and the ground motion data will be easier to access in a timely manner after an earthquake.

\subsection{Building Inventory Database}

Based on the Sixth National Population Census [10], this work constructs a virtual building inventory database of cities in the mainland of China. Specifically, according to the Sixth National Population Census, the number of buildings in the target region classified by the number of stories, structural type, and year built can be obtained. Note that these data are classified by one attribute. For example, the statistical data of the buildings for a typical region, Haidian District, are presented in Table 1. Therefore, the buildings are further divided into 33 categories according to the number of stories, structural type, and year built, such as the masonry structure built before 1990 with single story, and the masonry structure built before 1990 with two or three stories. The proportions of the 33 building types can be determined by solving the indefinite equations that describe this problem. Then a virtual city with 1000 buildings that reflects the statistical characteristics of local buildings can be established. The building inventory database of each region can be established to serve the subsequent seismic damage prediction. Note that if the statistical data of each building can be obtained for the target region, then these data can be directly used to establish the analysis model. In addition to the cities in the mainland of China, other building inventory databases for other regions (e.g., Japan and the United States) are under construction. As a result, the proposed method can be further applied to different regions if the ground motions and building inventory are available. 
Table 1. Statistical data of the buildings for Haidian District, Beijing.

\begin{tabular}{|c|c|c|c|c|c|}
\hline Number of stories & 1 & $2-3$ & $4-6$ & $7-9$ & $>9$ \\
\hline Proportions & $20.6 \%$ & $10.6 \%$ & $36.3 \%$ & $4.9 \%$ & $27.6 \%$ \\
\hline Year built & \multicolumn{2}{|c|}{$<1990$} & 1990-1999 & \multicolumn{2}{|r|}{$>1999$} \\
\hline Proportions & \multicolumn{2}{|c|}{$30.3 \%$} & $29.8 \%$ & \multicolumn{2}{|r|}{$39.9 \%$} \\
\hline Structural type & \multirow{2}{*}{\multicolumn{2}{|c|}{$\begin{array}{c}\text { Steel and reinforced concrete } \\
47.9 \%\end{array}$}} & Masonry & Wood & Other structures \\
\hline Proportions & & & $40.3 \%$ & $11.6 \%$ & $0.2 \%$ \\
\hline
\end{tabular}

\subsection{City-Scale Nonlinear Time-History Analysis}

The city-scale nonlinear time-history analysis is used to perform the seismic damage simulation for the target region [11]. In general, the buildings in a city can be divided into two types: Ordinary multi-story buildings and ordinary tall buildings. Multi-story buildings often exhibit shear deformation modes under earthquakes, whereas tall buildings will deform in flexural-shear modes. Thus, the multipledegree-of-freedom (MDOF) shear model will be used for the multi-story buildings (Figure 2a), and the MDOF flexural-shear model will be applied to tall buildings (Figure 2b). In the MDOF model, the masses of the buildings are concentrated on their corresponding stories. Specifically, for the MDOF shear model, each story is represented by a nonlinear spring, as shown in Figure 2a. For the MDOF flexural-shear model, each story is discretized into a nonlinear shear spring and a nonlinear flexural spring, which are connected to each other by rigid links, as shown in Figure $2 \mathrm{~b}$. The nonlinear behavior of the structure is represented by the nonlinear inter-story force-displacement relationships (Figure 2c). The tri-linear backbone curves recommended in the HAZUS report [7] are employed to model the inter-story force-displacement relationships. Note that the parameter determination of the inter-story force-displacement relationships is critical for the rationality and accuracy of the simulation results, considering the limited available information for buildings on a regional scale. The parameter determination methods for buildings in China and the United States proposed by the authors [11] are adopted in the city-scale nonlinear time-history analysis. For buildings in the other countries, the parameter determination procedure can refer to those two methods.

(a)

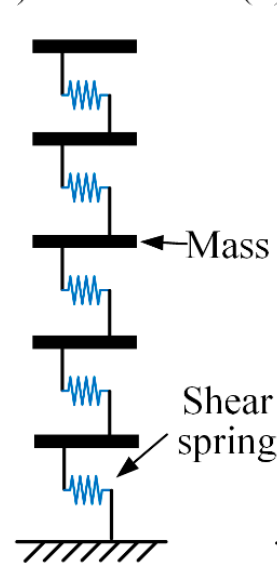

(b)

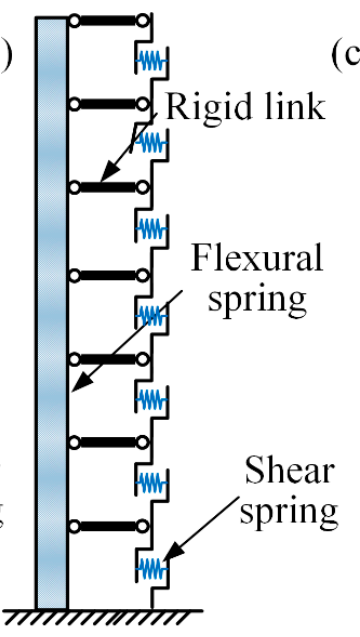

(c)

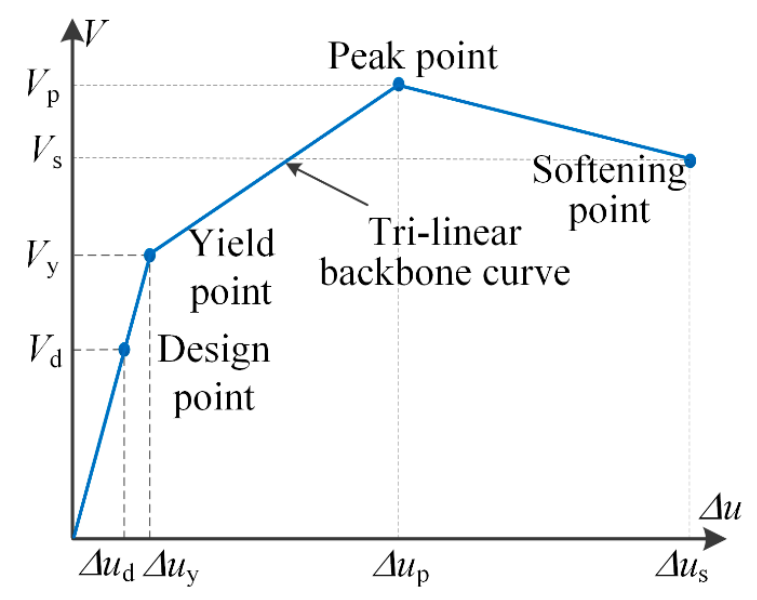

Figure 2. (a) Multiple-degree-of-freedom (MDOF) shear model; (b) MDOF flexural-shear model; and (c) trilinear backbone curve adopted in the MDOF model.

\subsubsection{Parameter Determination Method for Buildings in China}

The parameter determination method for buildings in China is based on the design codes and statistics of extensive experimental and analytical results [12,13]. Because the buildings usually have a regular layout along with the height, the stiffness and masses of different stories are assumed to be uniform [14]. The elastic parameters of a building can be represented by the inter-story shear stiffness, 
$k_{0}$, and the mass, $m$, of each story. Equations (1) and (2) show the global stiffness $[K]$ and mass matrices $[M]$ of a structure with a uniform stiffness and mass along the height [15].

$$
\begin{gathered}
{[K]=k_{0}\left[\begin{array}{ccccc}
2 & -1 & & & \\
-1 & 2 & -1 & & \\
& -1 & \ddots & \ddots & \\
& & \ddots & 2 & -1 \\
& & & -1 & 1
\end{array}\right]=k_{0}[A]} \\
{[M]=m\left[\begin{array}{lllll}
1 & & & & \\
& 1 & & & \\
& & 1 & & \\
& & & \ddots & \\
& & & & 1
\end{array}\right]=m[I]}
\end{gathered}
$$

The mass of each story, $m$, in Equation (2) can be determined based on the area of each story, $A_{1}$, and the mass per unit area, $m_{1}$ (Equation (3)) [16]; $m_{1}$ can be estimated according to the occupancy of each story.

$$
m=m_{1} A_{1}
$$

The relationship among the stiffness, mass, and first vibration period, $T_{1}$, can be expressed using Equation (4).

$$
k_{0}=m \omega_{1}^{2}\left(\frac{\left[\Phi_{1}\right]^{T}[I]\left[\Phi_{1}\right]}{\left[\Phi_{1}\right]^{T}[A]\left[\Phi_{1}\right]}\right)=\frac{4 \pi^{2} m}{T_{1}{ }^{2}}\left(\frac{\left[\Phi_{1}\right]^{T}[I]\left[\Phi_{1}\right]}{\left[\Phi_{1}\right]^{T}[A]\left[\Phi_{1}\right]}\right)
$$

where $\left[\Phi_{1}\right]$ is the first mode vector. Given the stiffness matrix $[K]$ and mass matrix $[M],\left[\Phi_{1}\right]$ can be computed using a generalized eigenvalue analysis. As shown in Equation (4), $m$ and $T_{1}$ are required to obtain $k_{0}$. The vibration periods of different types of structures can be estimated using empirical equations. For example, the fundamental period of a reinforced concrete $(\mathrm{RC})$ frame can be calculated using the empirical equation (Equation (5)) specified in the Chinese Code [17].

$$
T_{1}=0.25+0.00053 H^{2} / \sqrt[3]{B}
$$

where $H$ and $B$ are the height and width of an RC frame, respectively. For other types of structures (e.g., RC tall buildings, masonry structures, steel frames), the corresponding empirical vibration period can also be adopted to determine the inter-story stiffness.

For engineering-designed structures (e.g., RC frames and reinforced masonry structures), the design strength can be estimated according to the seismic design code. Therefore, an equivalent lateral force analysis can be used to calculate the design shear force, $V_{\text {design, } i}$, of each story, where $i$ is the story number $[18,19]$. Subsequently, according to related statistics of extensive experimental and analytical results, the yield point, peak point, and softening point on the backbone curve can be further obtained. For example, the yield point, peak point, and softening point of an RC frame can be determined by Equations (6)-(8) as follows:

$$
\begin{gathered}
V_{\text {yield }, i}=\Omega_{1} V_{\text {design, } i} \\
V_{\text {peak }, i}=\Omega_{2} V_{\text {design, } i} \\
V_{\text {ultimate, } i}=V_{\text {peak, } i}
\end{gathered}
$$

where $V_{\text {yield, } i}, V_{\text {peak, } i}$, and $V_{\text {ultimate } i}$ are the yield strength, peak strength, and ultimate strength, respectively. $\Omega_{1}$ is the yield overstrength ratio of RC frames, which is determined according to the 
partial factor of steel reinforcement [20]. $\Omega_{2}$ is the peak overstrength ratio, which is determined by the statistics of 155 pushover results of RC frames designed following the Chinese seismic design code. The deformation parameters of RC frames, including the yield, peak, and ultimate deformations, can be determined using the same procedure.

Non-engineered buildings (e.g., unreinforced masonry buildings and adobe buildings) lack a design strength as the reference strength to establish the backbone curve in Figure 2c. Consequently, the statistical strengths of different types of non-engineered buildings obtained from the literature are used to establish the backbone curve. For example, Xiong et al. [13] proposed using the statistical results of the peak strength per unit area of 1000 unreinforced masonry structures in China as the reference strength. The other parameters on the backbone curve of unreinforced masonry buildings are determined based on the statistical results of 97 unreinforced masonry wall experiments.

\subsubsection{Parameter Determination for Backbone Curve Based on the HAZUS Data}

Based on the HAZUS database, Lu et al. [15] also proposed a modeling approach by which all parameters of the MDOF shear model can be determined from the basic building information (i.e., number of stories, height, year built, structural type, floor area, and occupancy). Specifically, the first vibration period of the building can be determined by the typical buildings presented in Tables 5.5 and 5.7 of FEMA [7]. The elastic parameters of a building, including the inter-story shear stiffness, $k_{0}$, and the mass, $m$, are determined using Equations (1)-(4). Subsequently, the inter-story backbone curve parameters of story $i$ in Figure 3 are determined as follows:

$$
\begin{gathered}
k_{0, i}=\lambda \frac{4 \pi^{2} m}{T_{1}^{2}} \\
V_{\mathrm{y}, i}=S A_{\mathrm{y}} \cdot \alpha_{1} \cdot m \cdot g \cdot N \cdot \Gamma_{i} \\
\eta_{i}=\frac{S A_{\mathrm{u}}-S A_{\mathrm{y}}}{S D_{\mathrm{u}}-S D_{\mathrm{y}}} \cdot \frac{S D_{\mathrm{y}}}{S A_{\mathrm{y}}} \\
\beta_{i}=\frac{S A_{\mathrm{u}}}{S A_{\mathrm{y}}} \\
\Delta_{\mathrm{c}, i}=\delta_{\mathrm{Co}} \cdot h
\end{gathered}
$$

where $g$ is the acceleration of gravity; $\delta_{\mathrm{Co}}$ is the inter-story drift ratio at the threshold of the complete damage state, as suggested by HAZUS [7]; $h$ is the story height; $\left(S D_{\mathrm{y}}, S A_{\mathrm{y}}\right)$ and $\left(S D_{\mathrm{u}}, S A_{\mathrm{u}}\right)$ are the yield capacity point and ultimate capacity point, respectively, of the capacity curve suggested by HAZUS [7], which are functions of the design intensity and year built; $\alpha_{1}$ is the mode factor suggested by HAZUS [7]; and $\Gamma_{i}$ is the ratio between the inter-story shear strength of the $i$ th story, $\left(V_{y, i}\right)$ and that of the ground story $\left(V_{y, 1}\right)$, which is calculated as follows:

$$
\Gamma_{i}=\frac{V_{y, i}}{V_{y, 1}}
$$

A single-parameter pinching model (Figure 4) proposed by Steelman and Hajjar [21] is adopted to represent the pinching behavior subjected to cyclic loads. Five damage states, ranging from none, slight, and moderate, to extensive and complete damage, are considered, which are identical to the damage states defined by HAZUS. The inter-story drift ratio is used as the threshold for each structural damage state, and the values for different structural types are based on Table 5.9 of HAZUS [7]. 


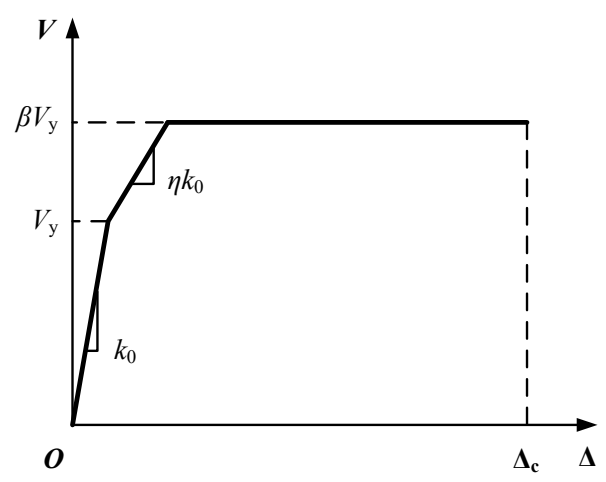

Figure 3. Backbone curve of the MDOF shear model.

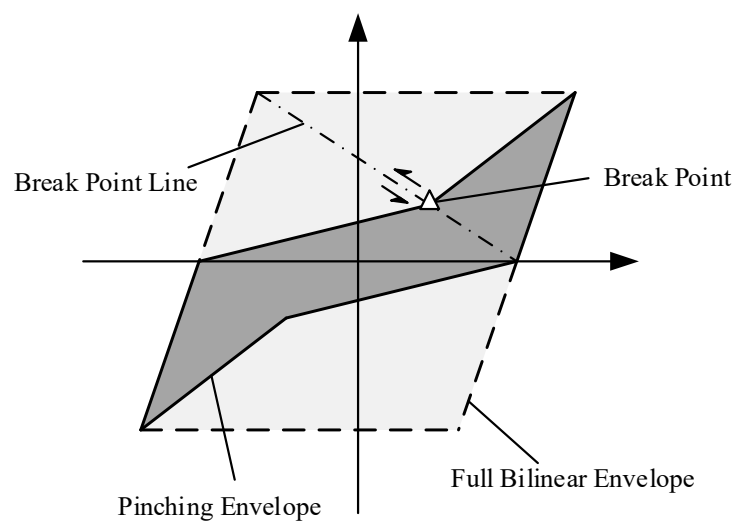

Figure 4. Diagram of the pinching envelope of the pinching model.

The classical Rayleigh damping model is adopted in the analysis. The empirical values of the damping ratio are estimated according to the structural type of the building [15]. For example, the damping ratio of steel structures equals 0.05 . It should be noted that the soil-structure-interaction (SSI) effects and structural eccentricity aren't considered in this work.

The reliability of the city-scale nonlinear time-history analysis method is further validated by comparing the simulation results with earthquake site investigations, experimental results, and a large number of numerical results [11]. With outstanding computational efficiency, this method can be used well for post-earthquake emergency responses. There exists an inherent uncertainty in the seismic performance of buildings, which is considered in this method by incorporating the parametric uncertainty of the building backbone curve [22]. Consequently, the proposed method can not only provide the building response using the median value of the backbone curve parameters but also provide the responses with the median value \pm one standard deviation to account for the parametric uncertainty, which is crucial for scientific decision-making.

The nonlinear time-history analysis of the buildings in the target area is implemented using the ground motions obtained from the seismic network. Subsequently, the time histories of the seismic response of each story in every building can be obtained. According to the engineering demand parameters (EDPs) and the damage criteria [11], the damage state of each building in the region is determined, based on which, the destructive power of the ground motion to the target area is evaluated. To make full use of the real-time earthquake ground motions obtained from the densely distributed seismic stations, the destructive powers of ground motions obtained from different seismic stations can be evaluated by inputting the ground motions one-by-one into the building models of the target region. The distribution of building damage ratios under different station records can be given subsequently, which provides an essential reference for post-earthquake rescue work. For example, the destructive power of ground motions of the 08/13/2018 M5.0 Yunnan Tonghai earthquake can be illustrated intuitively, as shown in Figure 5. 


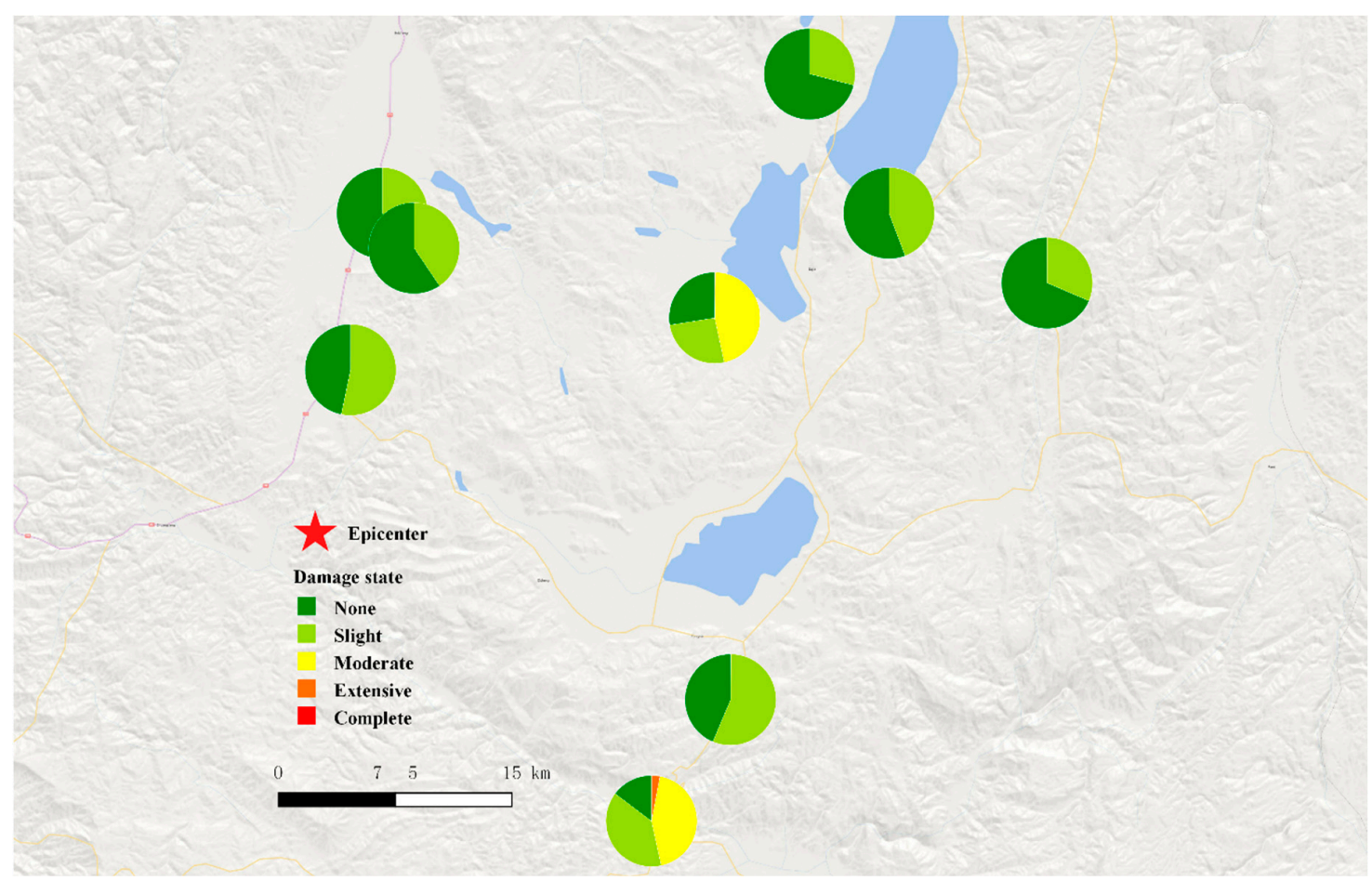

Figure 5. Destructive power of ground motions of the 08/13/2018 M5.0 Yunnan Tonghai earthquake.

The human sense of floor acceleration is highly important in the resilience assessment of communities under moderate seismic actions. Based on the comfort criteria [23] and floor acceleration computed by the nonlinear time-history analysis, the human sense of different ground motions can be obtained. The distribution of human uncomfortableness under the ground motions of the 11/26/2018 M6.2 Taiwan Strait earthquake is shown in Figure 6. Although the damage ratio of buildings under this earthquake is very small, the ratio of human uncomfortableness is still high.

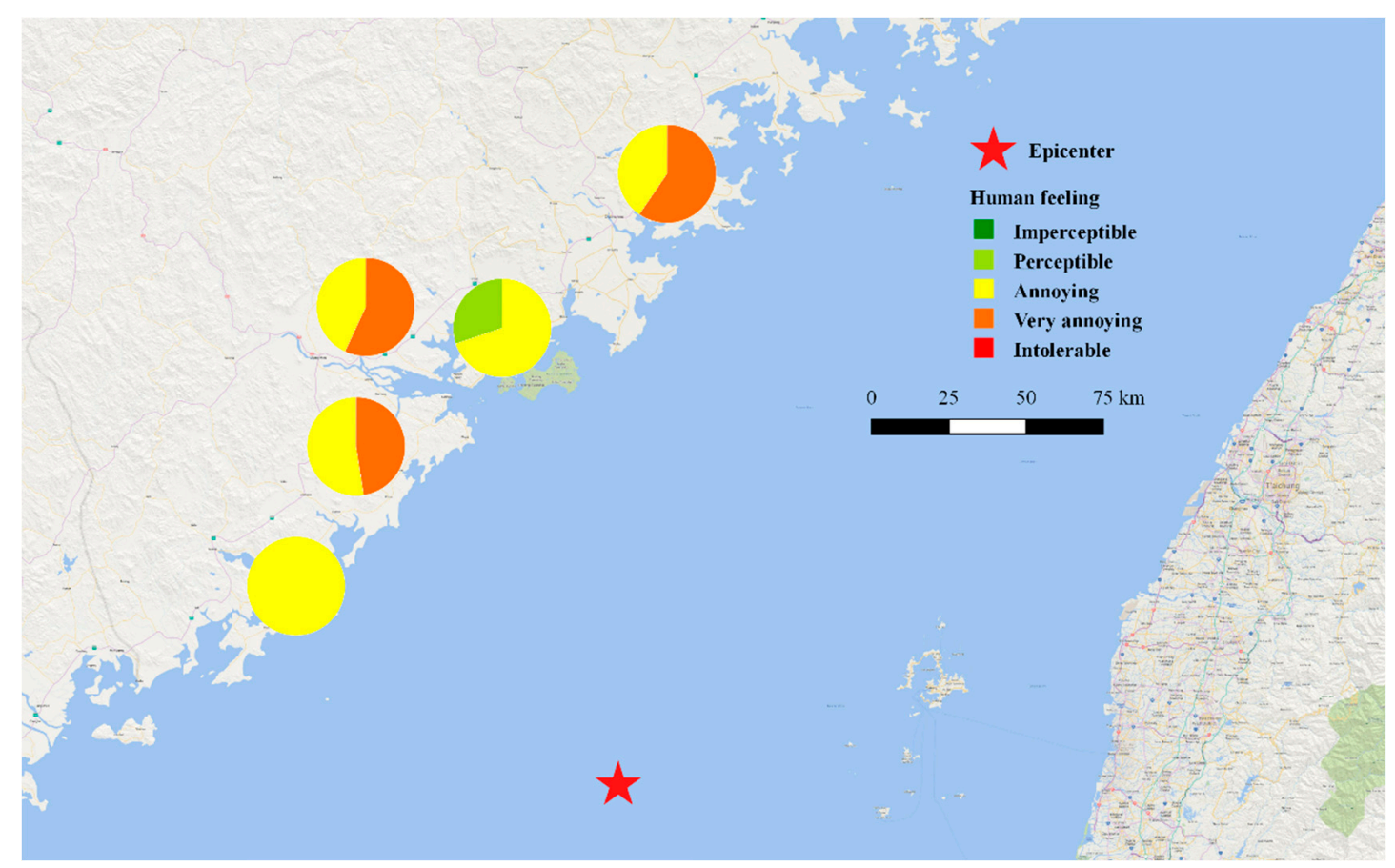

Figure 6. Distribution of human uncomfortableness under the ground motions of the 11/26/2018 M6.2 Taiwan Strait earthquake. 


\subsection{Regional Seismic Loss Prediction and Resilience Assessment}

\subsubsection{Regional Seismic Loss Prediction Using Conventional Method}

Based on the damage state of each building, the seismic loss can be predicted using the conventional loss prediction method. For example, according to the National Standard of China, "Post-Earthquake Field Works-Part 4: Assessment of Direct Loss" [24], the house damage loss $L_{h}$ and decoration damage loss $L_{d}$ are calculated using Equations (15) and (16), respectively:

$$
\begin{gathered}
L_{h}=S \times D_{h} \times P \\
L_{d}=\gamma_{1} \times \gamma_{2} \times(\xi \times S) \times D_{d} \times(\eta \times P)
\end{gathered}
$$

where $S$ is the building area $\left(\mathrm{m}^{2}\right) ; D_{h}$ and $D_{d}$ are the loss ratios of the house and decoration damage, given a damage state; $P$ is the building replacement cost; $\gamma_{1}$ is the correction factor considering different economic conditions of different regions; $\gamma_{2}$ is the building function correction factor; $\xi$ is the proportion of buildings with mid-to-high-quality decoration; and $\eta$ is the ratio of the building decoration cost to the building construction cost. The values of $\gamma_{1}, \gamma_{2}, \xi, \eta$ can be found in Table A.1-A.4 in GB/T 18208.4 [24].

\subsubsection{Regional Resilience Assessment Using FEMA P-58}

Furthermore, based on the FEMA P-58 method (next-generation seismic performance assessment method of buildings) and the city-scale nonlinear time-history analysis, a practical approach for regional resilience assessment is proposed [25] to give a more detailed seismic loss and repair-time prediction. The main process of the method is as follows: (a) Analyze the building response to determine the EDPs on each story of each building using the nonlinear MDOF models, and (b) calculate the economic loss and repair time of components based on the building performance models and the fragility data provided in the FEMA P-58 document. The flowchart of the repair cost calculation is shown in Figure 7. Using this method, the damage states of components on different stories can be obtained, and the loss caused by the floor displacement, acceleration, and residual displacement can be considered.

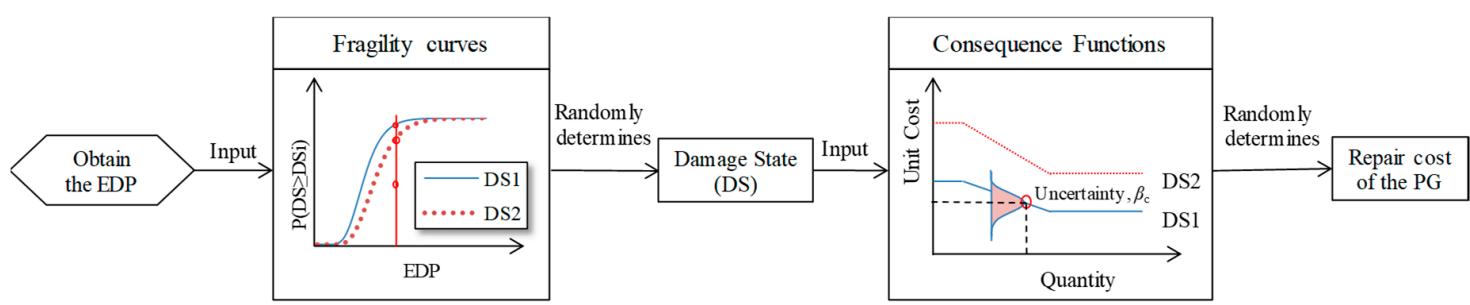

Figure 7. Calculation of repair cost for a building component using the FEMA-P58 methodology.

The repair time is calculated according to the FEMA P-58 method. Specifically, the corresponding repair time is determined according to the damage state of each component, and then the repair time of components in each story are summarized. Using the parallel repair strategy, the maximum repair time of each story is taken as the repair time of the building. Using high-efficiency computational codes, this method can quickly calculate the economic loss and repair time of earthquake-stricken areas.

One of the critical challenges of using the FEMA-P58 method in a region is the assembly of performance groups (PGs). The performance model of a building contains its basic information with both structural and nonstructural PGs. The types and quantities of building components can be obtained using the following three methods: (a) Field survey data and building design drawings, (b) building information models (BIM), and (c) the geographic information system (GIS) database. 
(a) Field survey data and building design drawings

The type and quantity of each structural PG can be obtained from the structural and architectural drawings of the building. The nonstructural PGs can be determined using the field survey. Note that some effort is required to collect the information. However, the data can be implemented in parallel by groups of people with basic knowledge of architectural and structural engineering.

\section{(b) Building information models}

The detailed building data can be automatically obtained from the BIM in which the building components have different levels of development (LODs). The determination of the component type and the development of a component vulnerability function when the information is incomplete are proposed to produce an acceptable loss prediction [26,27]. Specifically, the PGs in FEMA P-58 are organized as different classification trees. For example, the classification tree of a gypsum wall board (GWB) partition is shown in Figure 8. According to the LODs of the BIMs, all PGs that cannot be determined as leaf nodes in the classification tree due to lack of information will be treated as "potential fragility classifications." A Monte Carlo simulation is subsequently implemented considering all "potential fragility classifications." Consequently, the loss can be predicted even when a very coarse BIM is available. In addition, the modeling rules and information extraction for BIM are proposed to obtain the component information [26,27].

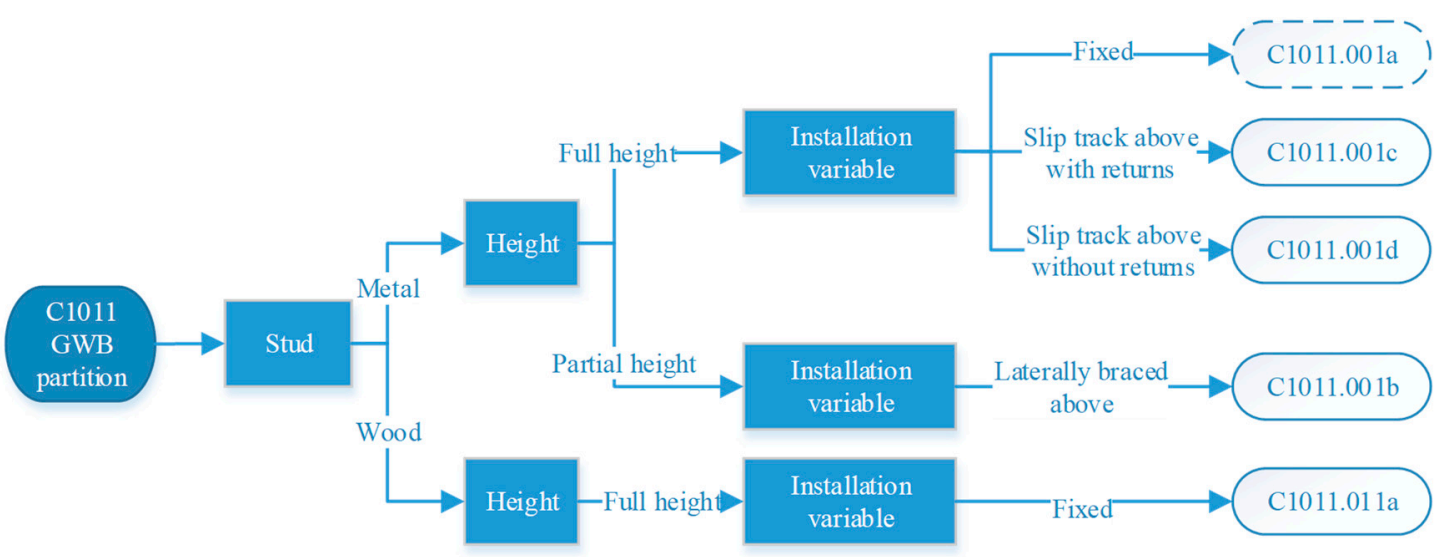

Figure 8. Classification tree of a gypsum wall board (GWB) partition component.

\section{(c) GIS database}

According to the building inventory of the GIS database, the structural component quantity is estimated based on the statistics from the available literature and design drawings. The nonstructural PG information can be identified according to the normative quantity information provided by Appendix F of FEMA [28]. Subsequently, the structural and nonstructural PGs can be estimated.

A new trend to efficiently and accurately establish the PGs of buildings on a regional scale uses the City Information Model (CIM). CIM is defined as the integration of GIS and BIM [29]. The CIM of the earthquake-stricken area can be pre-established, which will provide valuable data for the community resilience assessment on different scales.

To demonstrate the resilience assessment method for a region, the seismic economic loss and repair time of Tsinghua Campus [25] were calculated. The ground motion recorded at the Jiuzhaigou Baihe station was input to 619 buildings of Tsinghua Campus. The distribution of the median building loss ratios and repair/rebuilding times are shown in Figure 9. The total loss ratio is $0.576 \%$, which is very small. The repair time of the campus is 15 days with parallel repair strategies. The results provide a valuable reference for the resilience assessment of Tsinghua Campus. 


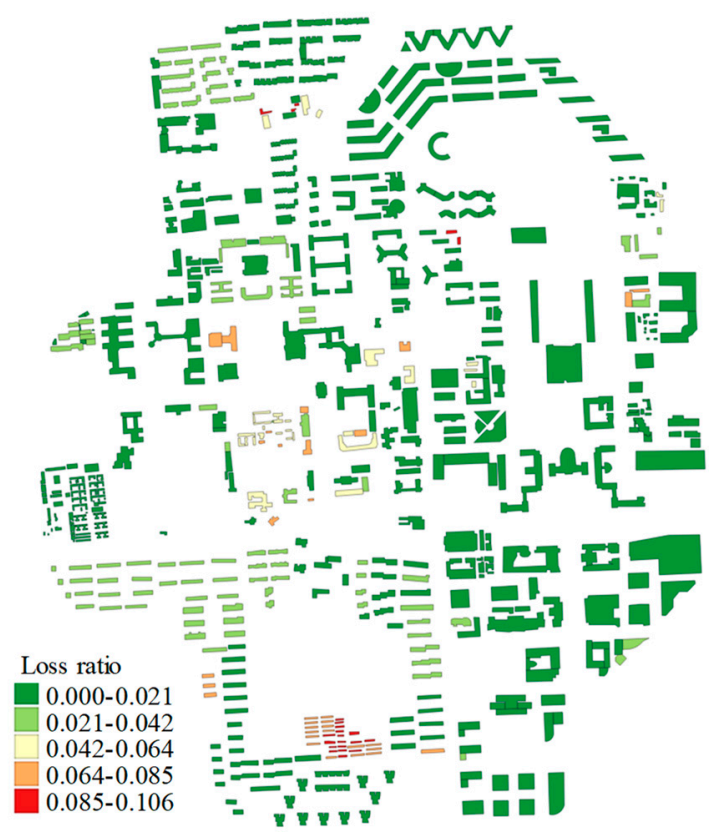

(a)

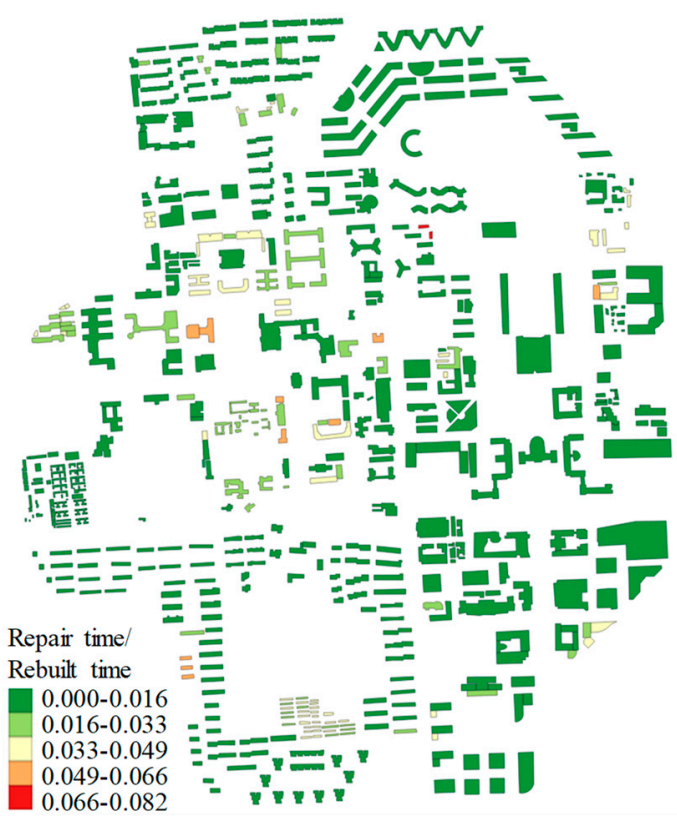

(b)

Figure 9. Distribution of median (a) building loss ratios and (b) repair/rebuild time for Tsinghua Campus.

\subsection{High-Performance Computing for Post-Earthquake Emergency Response}

High-performance computing (HPC) is incorporated to implement the real-time city-scale THA for the post-earthquake emergency response. The OpenMP library [30] is used to parallelize the code of the city-scale nonlinear time-history analysis. Only $136 \mathrm{~s}$ are required to complete the computation of a ground motion record (with an Intel Xeon E5 2630 @2.40 GHz CPU and 64 GB of RAM), which satisfies the requirement for the post-earthquake emergency response.

Furthermore, cloud computing is introduced to perform coarse-grain parallel analysis. Specifically, a number of virtual computers are quickly established (in minutes) on the cloud computing platform (e.g., Aliyun Cloud or Tencent Cloud) after an earthquake. Subsequently, the analyses of different ground motion records are assigned to different virtual computers. Each virtual computer has nearly the same performance as the local computing environment. Thus, regardless of how many ground motions are to be computed, the time consumption is almost the same as that of a single ground motion. Meanwhile, the computational cost is less than one US dollar for each virtual computer. Such a flexible cloud computing platform makes the real-time analysis of a number of ground motions technologically and economically feasible.

\section{Applications in Earthquake Emergency Response}

\subsection{Overview of the Applications}

When an earthquake occurs, the ground motion will be collected in a timely manner from the strong ground motion network. The real-time city-scale THA will be conducted for the target region, and the analysis results will be fed back to the decision-makers and reported on the internet in a short time. A program is developed named as "Real-time Earthquake Damage Assessment using City-scale Time-history analysis" ("RED-ACT" for short) to automatically implement the above workflow. This software is programmed in $\mathrm{C}++$ and runs on the Windows operating system. To date, RED-ACT system has been applied to several earthquakes in China and other countries around the world, as listed in Table 2. Typical applications will be introduced as follows. 
Table 2. Applications of the RED-ACT system.

\begin{tabular}{|c|c|c|c|}
\hline ID & Earthquake Name & ID & Earthquake Name \\
\hline 1 & 12/08/2016 M6.2 Xinjiang Hutubi earthquake & 18 & 11/26/2018 M6.2 Taiwan Strait earthquake \\
\hline 2 & 12/18/2016 M4.3 Shanxi Qingxu earthquake & 19 & 12/08/2018 M4.5 Xinjiang Changji earthquake \\
\hline 3 & 03/27/2017 M5.1 Yunnan Yangbi earthquake & 20 & 12/16/2018 M5.7 Sichuan Yibin earthquake \\
\hline 4 & 08/08/2017 M7.0 Sichuan Jiuzhaigou earthquake & 21 & 12/20/2018 M5.2 Xinjiang Kizilsu earthquake \\
\hline 5 & 09/30/2017 M5.4 Sichuan Qingchuan earthquake & 22 & 01/03/2019 M5.3 Sichuan Yibin earthquake \\
\hline 6 & 02/06/2018 M6.5 Taiwan Hualien earthquake & 23 & 01/07/2019 M4.8 Xinjiang Jiashi earthquake \\
\hline 7 & 02/12/2018 M4.3 Hebei Yongqing earthquake & 24 & 04/16/2016 M7.3 Japan Kumamoto earthquake \\
\hline 8 & 05/28/2018 M5.7 Jilin Songyuan earthquake & 25 & 08/24/2016 M6.2 Italy earthquake \\
\hline 9 & 08/13/2018 M5.0 Yunnan Tonghai earthquake & 26 & 11/13/2016 M8.0 New Zealand earthquake \\
\hline 10 & 08/14/2018 M5.0 Yunnan Tonghai earthquake & 27 & 09/20/2017 M7.1 Mexico earthquake \\
\hline 11 & 09/04/2018 M5.5 Xinjiang Jiashi earthquake & 28 & 11/23/2017 M7.8 Iraq earthquake \\
\hline 12 & 09/08/2018 M5.9 Yunnan Mojiang earthquake & 29 & 06/18/2018 M6.1 Japan Osaka earthquake \\
\hline 13 & 09/12/2018 M5.3 Shanxi Ningqiang earthquake & 30 & 09/06/2018 M6.9 Japan Hokkaido earthquake \\
\hline 14 & 10/16/2018 M5.4 Xinjiang Jinghe earthquake & 31 & 10/26/2018 M5.4 Japan Hokkaido earthquake \\
\hline 15 & 10/31/2018 M5.1 Sichuan Xichang earthquake & 32 & 12/01/2018 M7.0 Alaska earthquake \\
\hline 16 & 11/04/2018 M5.1 Xinjiang Atushi earthquake & 33 & 01/03/2019 M6.2 Japan Kumamoto earthquake \\
\hline 17 & 11/25/2018 M5.1 Xinjiang Bole earthquake & & \\
\hline
\end{tabular}

\subsection{M7.0 Jiuzhaigou Earthquake}

The seismic damage assessment of the 2017 Jiuzhaigou earthquake is a typical application case [31]. After the earthquake, several sets of ground motion records were obtained from the seismic network, and the seismic damage prediction of the target region was completed in $2 \mathrm{~h}$ (including the time for the data checking and report editing/publishing) by using the method proposed. The predicted damage of a typical town and country in the Aba region under the ground motion of the Jiuzhaigou Baihe station is shown in Figure 10. The predicted results show that the buildings in the disaster area may be damaged to some extent, but the ratio of collapse is very small, which is consistent with the actual post-earthquake site investigations [32]. The results provide a useful reference for the earthquake emergency response and scientific decision-making of earthquake disaster relief.

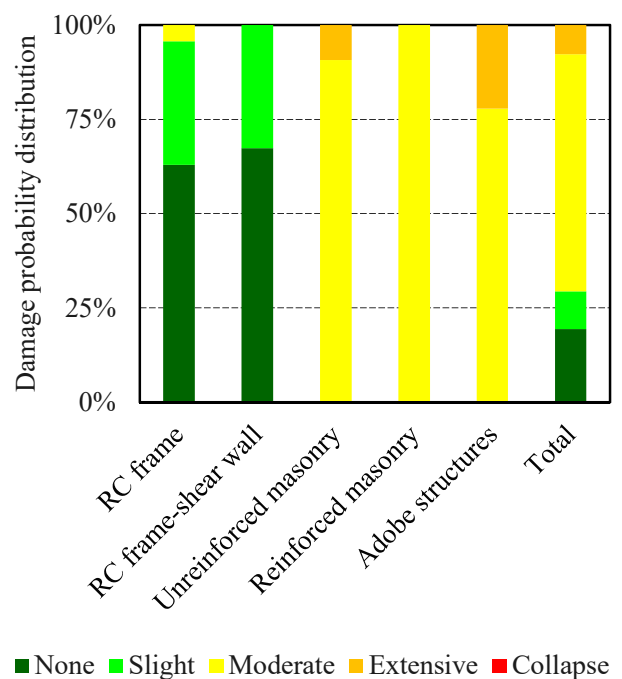

(a)

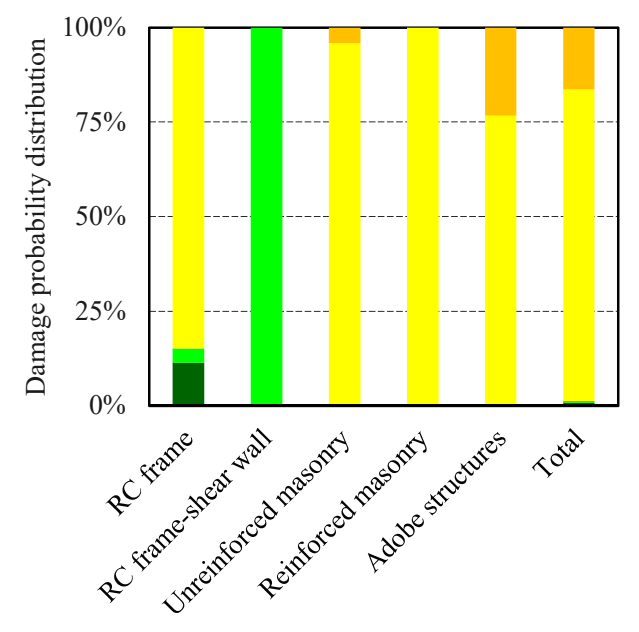

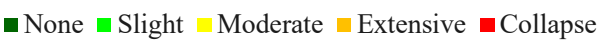

(b)

Figure 10. Seismic results of a (a) typical town and (b) country in the Aba region subjected the ground motion from the Jiuzhaigou Baihe station. 


\section{3. $2018 M_{w}$ 7.0 Anchorage Earthquake}

The seismic damage assessment of the $2018 \mathrm{M}_{\mathrm{w}} 7.0$ Anchorage earthquake is another typical application case [33]. On 30 November 2018 (local time), a $\mathrm{M}_{\mathrm{w}} 7.0$ earthquake occurred in Alaska, the United States. The epicenter was at $61.35 \mathrm{~N}, 150.06 \mathrm{~W}$ with a depth of $40 \mathrm{~km}$ [34]. Six ground motions of the Anchorage earthquake event were recorded. The ground motions recorded at the 8047 station (61.189 N, 149.802 W, shown in Figure 11) are typical ground motions [35]. The peak ground accelerations (PGAs) of horizontal and vertical components of the 8047-ground motion were $807.162 \mathrm{~cm} / \mathrm{s}^{2}$ and $367.243 \mathrm{~cm} / \mathrm{s}^{2}$, respectively. The ground motions are shown in Figure 11 .
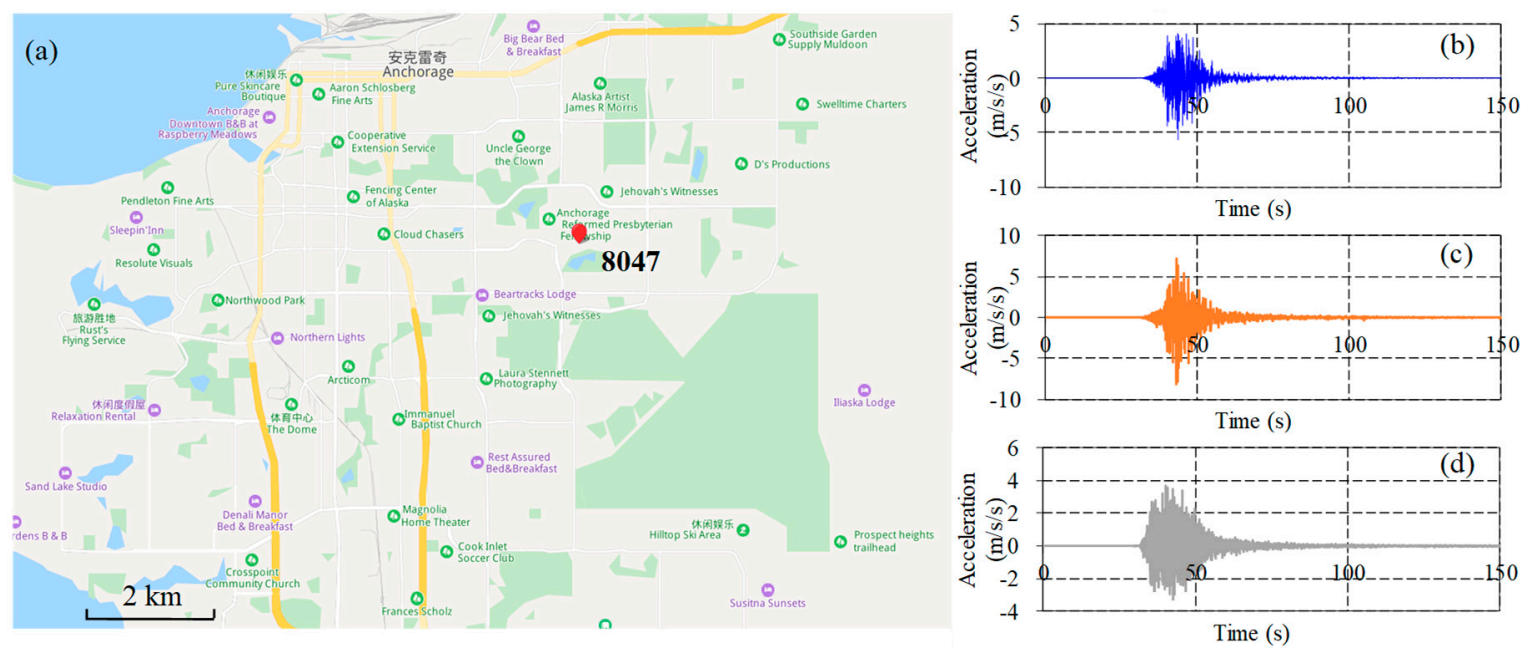

Figure 11. (a) Location of the 8047-ground motion station, and the ground motion recorded by the 8047 station: (b) EW direction, (c) NS direction, (d) UD direction.

Using the ground motions obtained from the strong motion networks and the city-scale nonlinear time-history analysis, the "RED-ACT" system predicted the damage ratio and human uncomfortableness distribution of the buildings near different stations in less than $1 \mathrm{~h}$, as shown in Figures 12 and 13. The post-earthquake investigation showed that this Mw 7.0 earthquake produced less-than-expected damage to buildings, including businesses, homes, and schools in downtown Anchorage, with most damage limited to nonstructural elements and contents [34], which is consistent with the prediction given by the proposed method.

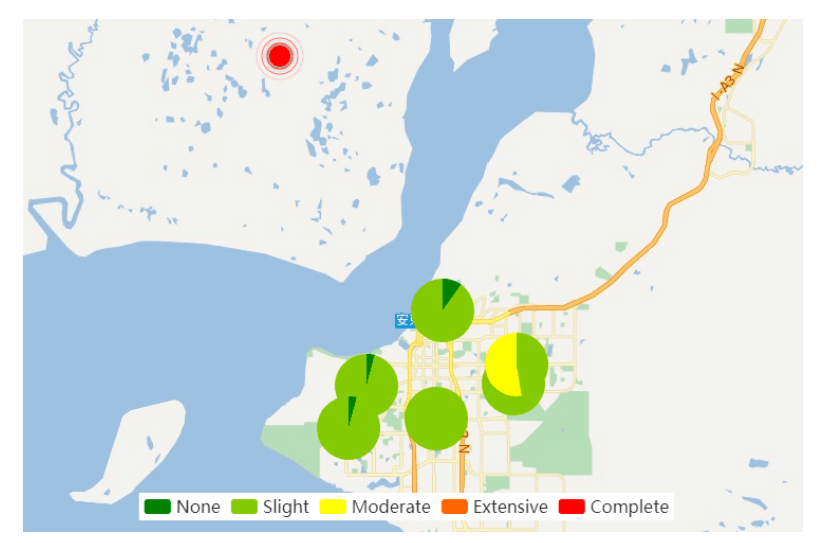

(a)

Figure 12. Cont. 


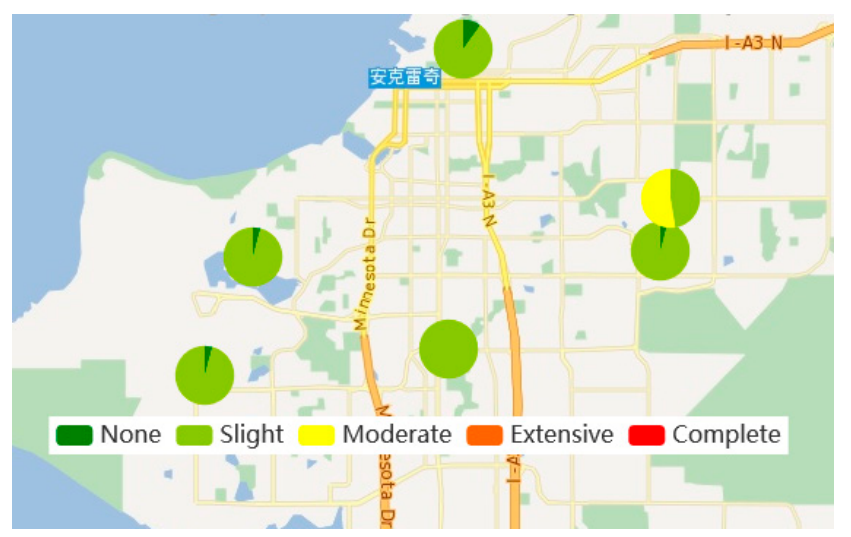

(b)

Figure 12. Damage ratio distribution of the buildings near different stations of the $2018 \mathrm{M}_{\mathrm{w}} 7.0$ Anchorage earthquake: (a) Global view, and (b) local view.

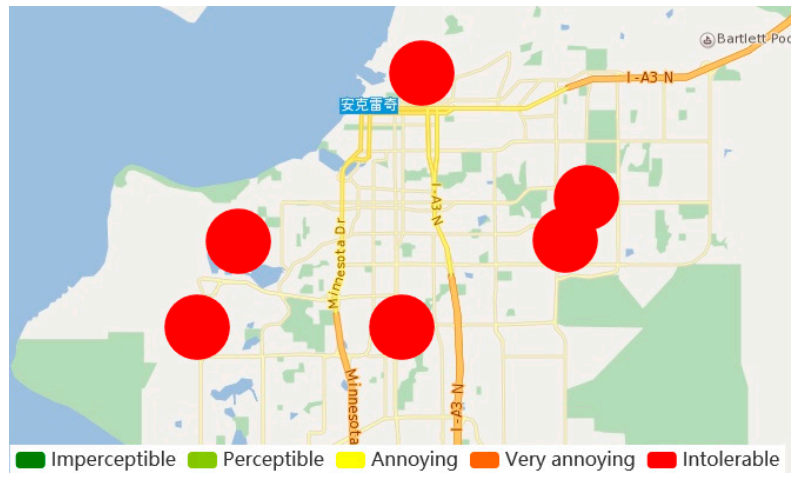

Figure 13. Distribution of human uncomfortableness under the ground motions of the $2018 \mathrm{M}_{\mathrm{W}} 7.0$ Anchorage earthquake.

\section{Conclusions}

Based on the city-scale nonlinear time-history analysis and the regional seismic loss prediction, a real-time city-scale time-history analysis method is proposed in this work. A program named "RED-ACT" was developed to automatically implement the described workflow. The reliability and advantages of the proposed method in this work were demonstrated through actual earthquake events. Then the program was applied to various earthquake events. The main conclusions are as follows:

(1) The uncertainty problem of ground motion input is solved properly with the proposed method based on the real-time ground motion obtained from the seismic stations;

(2) The amplitude, spectrum, and duration characteristics of ground motions, as well as the stiffness, strength, and deformation characteristics of different buildings are fully considered in this method, based on the nonlinear time-history analysis and MDOF models;

(3) Using the real-time city-scale time-history analysis and the corresponding report system, the assessment of the earthquake's destructive power, repair time, and economic loss can be obtained shortly after an earthquake event, which provides a useful reference for scientific decision-making for earthquake disaster relief. This work is highly significant to enhancing the resilience of earthquake-stricken areas.

Author Contributions: X.L. conceived the concept and guided the research, Q.C. conducted the analytical work and wrote the manuscript, and Z.X., Y.X. and C.S. reviewed the manuscript.

Funding: The authors are grateful for the financial support received from the National Key R\&D Program (number 2018YFC1504401). 
Acknowledgments: The authors are grateful for the ground motion data provided by the China Earthquake Networks Center, the Center for Engineering Strong Motion Data (CESMD), K-NET, and KiK-net.

Conflicts of Interest: The authors declare no conflict of interest.

\section{References}

1. Erdik, M.; Şeşetyan, K.; Demircioğlu, M.B.; Hancılar, U.; Zülfikar, C. Rapid earthquake loss assessment after damaging earthquakes. Soil Dyn. Earthq. Eng. 2011, 31, 247-266. [CrossRef]

2. Wald, D.J.; Jaiswal, K.; Marano, K.D.; Bausch, D.B.; Hearne, M.G. PAGER—Rapid Assessment of an Earthquake's Impact; U.S. Geological Survey Fact Sheet 2010-3036; U.S. Geological Survey: Reston, VA, USA, 2010.

3. GDACS. Global Disaster Alert and Coordination System. Available online: http://www.gdacs.org (accessed on 11 August 2019).

4. Trendafiloski, G.; Wyss, M.; Rosset, P. Loss estimation module in the second generation software QLARM. In Human Casualties in Earthquakes; Springer: Dordrecht, The Netherlands, 2011; pp. 95-106.

5. Erdik, M.; Fahjan, Y. Damage scenarios and damage evaluation. In Assessing and Managing Earthquake Risk; Springer: Dordrecht, The Netherlands, 2008; pp. 213-237.

6. Applied Technology Council (ATC). Earthquake Damage Evaluation Data for California; ATC-13; Applied Technology Council: Redwood City, CA, USA, 1985.

7. Federal Emergency Management Agency (FEMA). Multi-hazard Loss Estimation Methodology-Earthquake Model Technical Manual (HAZUS-MH 2.1); Final Report; Federal Emergency Management Agency: Washington, DC, USA, 2012.

8. Morfidis, K.; Kostinakis, K. Approaches to the rapid seismic damage prediction of r/c buildings using artificial neural networks. Eng. Struct. 2018, 165, 120-141. [CrossRef]

9. De Lautour, O.R.; Omenzetter, P. Prediction of seismic-induced structural damage using artificial neural networks. Eng. Struct. 2009, 31, 600-606. [CrossRef]

10. Population Census Office under the State Council, Department of Population and Employment Statistics of National Bureau of Statistics. Tabulation on the 2010 Population Census of the People's Republic of China; China Statistics Press: Beijing, China, 2012. (In Chinese)

11. Lu, X.Z.; Guan, H. Nonlinear MDOF Models for Earthquake Disaster Simulation of Urban Buildings. In Earthquake Disaster Simulation of Civil Infrastructures: From Tall Buildings to Urban Areas; Springer: Singapore, 2017; pp. 257-301.

12. Xiong, C.; Lu, X.Z.; Guan, H.; Xu, Z. A nonlinear computational model for regional seismic simulation of tall buildings. Bull. Earthq. Eng. 2016, 14, 1047-1069. [CrossRef]

13. Xiong, C.; Lu, X.Z.; Lin, X.C.; Xu, Z.; Ye, L.P. Parameter determination and damage assessment for THA-based regional seismic damage prediction of multi-story buildings. J. Earthq. Eng. 2017, 21, 461-485. [CrossRef]

14. Hori, M. Introduction to Computational Earthquake Engineering; Imperial College Press: London, UK, 2006.

15. Lu, X.Z.; Han, B.; Hori, M.; Xiong, C.; Xu, Z. A coarse-grained parallel approach for seismic damage simulations of urban areas based on refined models and GPU/CPU cooperative computing. Adv. Eng. Softw. 2014, 70, 90-103. [CrossRef]

16. Sobhaninejad, G.; Hori, M.; Kabeyasawa, T. Enhancing integrated earthquake simulation with high performance computing. Adv. Eng. Softw. 2011, 42, 286-292. [CrossRef]

17. GB50009-2012. Load Code for Design of Building Structures (GB 50009-2012); Ministry of Housing and Urban-Rural Development of the People's Republic of China (MOHURD): Beijing, China, 2012.

18. American Society of Civil Engineers (ASCE). Minimum Design Loads for Buildings and Other Structures (ASCE/SEI 7-10); American Society of Civil Engineers (ASCE): Reston, VA, USA, 2010.

19. GB50011-2010. Code for Seismic Design of Buildings (GB50011-2010); Ministry of Housing and Urban-Rural Development of the People's Republic of China (MOHURD): Beijing, China, 2010.

20. GB50010-2010. Code for Seismic Design of Concrete Structures (GB50010-2010); Ministry of Housing and Urban-Rural Development of the People's Republic of China (MOHURD): Beijing, China, 2010.

21. Steelman, J.S.; Hajjar, J.F. Influence of inelastic seismic response modeling on regional loss estimation. Eng. Struct. 2009, 31, 2976-2987. [CrossRef] 
22. Lu, X.Z.; Tian, Y.; Guan, H.; Xiong, C. Parametric sensitivity study on regional seismic damage prediction of reinforced masonry buildings based on time-history analysis. Bull. Earthq. Eng. 2017, 15, 4791-4820. [CrossRef]

23. Simiu, E.; Scanlan, R.H. Wind Effects on Structures: Fundamentals and Applications to Design, 3rd ed.; John Wiley: New York, NY, USA, 1996; p. 512.

24. GB/T18208. Post-Earthquake Field Works_Part 4: Assessment of Direct Loss (GB/T 18208.4-2011); Standardization Administration of China: Beijing, China, 2011. (In Chinese)

25. Zeng, X.; Lu, X.Z.; Yang, T.Y.; Xu, Z. Application of the FEMA-P58 methodology for regional earthquake loss prediction. Nat. Hazards 2016, 83, 177-192. [CrossRef]

26. Xu, Z.; Lu, X.Z.; Zeng, X.; Xu, Y.J.; Li, Y. Seismic loss assessment for buildings with various-LOD BIM data. Adv. Eng. Inf. 2019, 39, 112-126. [CrossRef]

27. Zeng, X. Direct Seismic Loss Assessment and Fire Following Earthquake Simulation of Urban Buildings. Ph.D. Thesis, Tsinghua University, Beijing, China, 2018. (In Chinese).

28. Federal Emergency Management Agency (FEMA). Seismic Performance Assessment of Buildings; Methodology; Technical Report FEMA-P58; Federal Emergency Management Agency (FEMA): Washington, DC, USA, 2012; Volume 1.

29. Xu, X.; Ding, L.Y.; Luo, H.B.; Ma, L. From building information modeling to city information modeling. J. Inf. Technol. Constr. 2014, 19, 292-307.

30. Chandra, R.; Dagum, L.; Kohr, D.; Menon, R.; Maydan, D.; McDonald, J. Parallel Programming in OpenMP; Morgan Kaufmann: San Diego, CA, USA,, 2001; pp. 8-14.

31. Lu, X.Z.; Gu, D.L.; Lin, X.C.; Cheng, Q.L.; Zhang, L.; Tian, Y.; Zeng, X. Seismic damage assessment of the ground motion near the epicenter of the 7.0 earthquake in Jiuzhaigou, Sichuan. Stand. Eng. Constr. 2017, 68-73. (In Chinese)

32. Dai, J.W.; Sun, B.T.; Li, S.Y.; Tao, Z.R.; Ma, Q.; Zhang, L.X.; Lin, J.Q. Engineering Damage in Jiuzhaigou M 7.0 Earthquake; Seismological Press: Beijing, China, 2018; p. 18. (In Chinese)

33. Lu, X.Z. Damage Capacity of the Ground Motions of the Dec. 1, Alaska Earthquake; Research Group Report; Tsinghua University: Beijing, China, 2018.

34. Structural Extreme Event Reconnaissance Network (StEER), Earthquake Engineering Research Institute (EERI). Alaska Earthquake Preliminary Virtual Assessment Team (P-VAT) Joint Report; Earthquake Engineering Research Institute: Oakland, CA, USA, 2018.

35. Center for Engineering Strong Motion Data (CESMD). Available online: https://www.strongmotioncenter. org/cgi-bin/CESMD/iqrStationMap.pl?ID=us1000hyfh (accessed on 26 January 2019). 